\title{
High Levels of Chromosomal Differentiation in Euchroma gigantea L. 1735 (Coleoptera, Buprestidae)
}

\author{
Rita de Cássia de Moura ${ }^{1,2}$, Natoniel Franklin de Melo ${ }^{3}$ and Maria José de Souza ${ }^{1}$ \\ ${ }^{1}$ Departamento de Genética, Centro de Ciências Biológicas, Universidade Federal de Pernambuco, \\ Recife, PE, Brazil. \\ ${ }^{2}$ Departamento de Biologia, Instituto de Ciências Biológicas, Universidade de Pernambuco, Recife, \\ PE, Brazil. \\ ${ }^{3}$ Embrapa Semi-Árido, Petrolina, PE, Brazil.
}

\begin{abstract}
Euchroma gigantea was karyotypically studied using conventional staining, C-banding, silver nitrate staining and ribosomal fluorescent in situ hybridization (rDNA FISH). Broad wide autosomal polymorphism and a complex sex determination system were found in this beetle. Karyotype complements ranging from $2 n=32, X_{1} X_{2} X_{3} Y_{1} Y_{2} Y_{3}$ to $2 n=36, X_{1} X_{2} X_{3} Y_{1} Y_{2} Y_{3}$ were detected in the sample analyzed. Punctiform supernumerary chromosomes were present in the different karyotypes. The karyotypic evolution of Brazilian E. gigantea may have taken two directions, reduction in the diploid number of $2 n=36$ to 24 through centric fusions or $2 n=24$ to 36 due to chromosomal fissions. In addition, pericentric inversions were also involved. The complex multiple sex mechanism of this species seems to be old and well established since it is found in specimens from different populations. Small pericentromeric blocks of constitutive heterochromatin were located on the autosomes and terminal blocks were also found on some small pairs. The sex chromosomes showed larger constitutive heterochromatin blocks. Silver nitrate staining during prophase I of meiosis showed labeling of the sex chromosome chain. However, the rDNA sites could only be precisely determined by FISH, which permitted the identification of these ribosomal sites on chromosomes $X_{1}$ and $X_{2}$ of this species.
\end{abstract}

Key words: chromosome polymorphism, C-banding, multiple sex system, NOR, rDNA.

Received: July 6, 2007; Accepted: October 1, 2007.

\section{Introduction}

The monotypic beetle genus Euchroma (Buprestidae), also known as the jewel scarab beetle, is widely distributed in the Neotropics and some subspecies and varieties of this genus have been described in South America, such as Euchroma gigantea mrazi found in southeastern Brazil (Obenberger, 1928).

Chromosome studies involving representatives of the family Buprestidae are scarce and only about 83 species having so far been analyzed by conventional methods, corresponding to $0.55 \%$ of all species described. The Buprestidae is characterized by a wide chromosome variability, with the diploid number ranging from $2 \mathrm{n}=12$ (Melanophila acuminata) to $2 \mathrm{n}=46$ (Sphenoptera scovitzi), and sex chromosome mechanisms of the chiasmatic (neo XY, $\mathrm{Xy}_{\mathrm{r}}, \mathrm{X}_{1} \mathrm{Y}_{1} \mathrm{X}_{2} \mathrm{Y}_{2} \mathrm{X}_{3} \mathrm{Y}_{3}$ ) and achiasmatic type

Send correspondence to Rita de Cássia de Moura. Departamento de Biologia, Instituto de Ciências Biológicas, Universidade de Pernambuco, Rua Arnóbio Marques 310, Santo Amaro, 50100-130 Recife, PE, Brazil. E-mail: rita_upe @yahoo.com.br.
$\left(\mathrm{Xy}_{\mathrm{p}}, \mathrm{XO}, \mathrm{Xy}\right.$, (Smith and Virkki, 1978; Mesa and Fontanetti, 1984; Karagyan and Kuznetsova, 2000; Karagyan, 2001; Karagyan et al., 2004). Various karyotypes have been described in E. gigantea, such as $2 \mathrm{n}=26$, Xy in specimens from Panama (Nichols, 1910), $2 \mathrm{n}=24$, $\mathrm{X}_{1} \mathrm{X}_{2} \mathrm{X}_{3} \mathrm{Y}_{1} \mathrm{Y}_{2} \mathrm{Y}_{3}$ and $2 \mathrm{n}=26, \mathrm{X}_{1} \mathrm{X}_{2} \mathrm{X}_{3} \mathrm{Y}_{1} \mathrm{Y}_{2}$ in specimens from the Brazilian state of São Paulo. In addition to chromosome polymorphism, this species presents the largest number of supernumerary chromosomes (16, 20 and 32) reported for the Coleoptera (Mesa and Fontanetti, 1984).

Most coleopteran species possess a simple sex mechanism, with only $3.4 \%$ of the species analyzed presenting a multiple sex mechanism. According to Virkki (1984), the $\mathrm{Xy}_{\mathrm{p}}$ sex system may not be the ancestral mechanism in this order, although it is apparently the most successful, being present in most species analyzed. Various families representative of the suborders Adephaga and Polyphaga present derived mechanisms such as XO or multiple sex systems. These mechanisms may have resulted from translocations between the $\mathrm{X}_{\mathrm{p}}$ and $\mathrm{y}_{\mathrm{p}}$ chromosomes and autosomes (Virkki, 1984). Examples of multiple systems have been 
described in the Tenebrionidae, Cincindelidae, Curculionidae and Chrysomelidae (Wahrman et al., 1973; Panzera et al., 1983; Postiglioni et al., 1987; Galián et al., 1995; Vitturi et al., 1996).

Autosomal polymorphisms involving chromosome fusions and dissociations (Smith and Virkki, 1978; Boyce et al., 1994), as well as the presence of supernumerary chromosomes (Smith and Virkki, 1978; Virkki and SantiagoBlay, 1993; Mesa and Fontanetti, 1984; Serrano et al., 1998), have been reported for different coleopteran species.

The aim of the research described in this paper was to analyze the meiotic and mitotic chromosomes of $E$. gigantea using conventional staining, C-banding, silver nitrate staining and fluorescent in situ hybridization (FISH) with a rDNA probe. Comparison of the results with data in the literature permitted a better chromosome characterization and the elaboration of a hypothesis on the karyotype evolution of this species.

\section{Material and Methods}

We analyzed 19 Euchroma gigantea L. 1735 specimens, the sample being made up of 15 males collected at the Igarassú Charles Darwin Ecological Refuge in the northeastern Brazilian state of Pernambuco $\left(7^{\circ} 50^{\prime} 3^{\prime \prime} \mathrm{S}\right.$, $\left.34^{\circ} 54^{\prime} 23^{\prime \prime} \mathrm{W}\right)$ and two males and two females collected from the Atlantic Rainforest in the Recife Zoo-Botanical Park in Pernambuco ( $8^{\circ} 3^{\prime} 14^{\prime \prime}$ S, 34 $\left.4^{\circ} 52^{\prime} 52^{\prime \prime} \mathrm{W}\right)$. The beetles were and the testes and ovaries dissected out and fixed in Carnoy's solution (ethanol:acetic acid 3:1 v/v). Cytological preparations were obtained using the classical testicular and ovarian follicles squashing method and the chromosomes were stained with $2 \%(\mathrm{w})$ lacto-acetic orcein. The method of Sumner (1972) was used for C-banding and silver nitrate staining was carried out as described by Rufas et al. (1987). The FISH was performed according to the method of Moscone et al. (1996) using a probe containing Arabidopsis thaliana $45 \mathrm{~S}$ ribosomal genes (18S, 5.8S, 25S) (Unfried et al., 1989; Unfried and Gruendler, 1990). The probes were labeled with biotin11-dUTP and detected with rat antibiotin antibody (Dakopatts M0743, Dako) and antiantibiotin antibody conjugated with tetramethyl-rhodamine isothiocyanate (TRITC). The preparations were counterstained with $2 \mu \mathrm{g} \mathrm{mL}^{-1}$ 4'-6-diamidino-2-phenylindole (DAPI) AT-specific fluorochrome and mounted with Vectashield H-1000 (Vector). The slides submitted to the different techniques were analyzed using a Leica photomicroscope and Kodak Imagelink 25, TMAX 400 and Fugi film 400 for FISH. Photographic copies were obtained using Kodak Kodabrome F3 paper.

\section{Results}

Chromosome analysis of E. gigantea showed the presence of a multiple sex determination mechanism of the $\mathrm{X}_{1} \mathrm{X}_{2} \mathrm{X}_{3} \mathrm{Y}_{1} \mathrm{Y}_{2} \mathrm{Y}_{3}$ type in males and wide autosomal poly- morphism. Five or six punctiform supernumerary chromosomes were also observed in the different karyotypes (Figure $1 \mathrm{~b}, \mathrm{~d})$. Two of the 15 specimens collected in Igarassú presented a $2 n=36, X_{1} X_{2} X_{3} Y_{1} Y_{2} Y_{3}$ karyotype in which all the autosomes were acrocentric (Figure 1a), 10 specimens showed a $2 n=34, X_{1} X_{2} X_{3} Y_{1} Y_{2} Y_{3}$ karyotype with one submetacentric and 13 acrocentric autosomal pairs (Figure 1b) while the other three specimens had a $2 \mathrm{n}=32$, $\mathrm{X}_{1} \mathrm{X}_{2} \mathrm{X}_{3} \mathrm{Y}_{1} \mathrm{Y}_{2} \mathrm{Y}_{3}$ karyotype with two submetacentric and 11 acrocentric autosomal pairs (Figure $1 \mathrm{~d}$ ). In addition, a heterozygous karyotype complement with $2 \mathrm{n}=33$ was observed in one specimen from the Recife population (Figure 1c), while the other specimens from this locality presented a $2 n=34, X_{1} X_{2} X_{3} Y_{1} Y_{2} Y_{3}$ karyotype. The $X$ chromosomes were submetacentric, the $Y_{1}$ and $Y_{2}$ chromosomes were metacentric and the $\mathrm{Y}_{3}$ chromosome was acrocentric (Figure $2 b, c)$. The sex mechanism was complex and chiasmatic. During metaphase I, the sex chromosomes were connected by distal chiasmata and formed an alternate chain with a sequence of $X_{1}-Y_{1}-X_{2}-Y_{2}-X_{3}-Y_{3}$ (Figure 2a).

In E. gigantea, constitutive heterochromatin $(\mathrm{CH})$ was located in the pericentromeric region of all autosomes. In addition, some small pairs contained terminal $\mathrm{CH}$ blocks (Figure 3a). Chromosomes $\mathrm{X}_{1}$ and $\mathrm{X}_{3}$ possessed centromeric $\mathrm{CH}$, and the long arm of chromosome $\mathrm{X}_{1}$ was almost completely heterochromatic. In the case of the $\mathrm{X}_{2}$ chromosome, $\mathrm{CH}$ was only present in the terminal region of the short arm. Chromosome $Y_{1}$ showed an almost completely heterochromatic short arm, in addition to an interstitial block on the long arm. The $\mathrm{Y}_{2}$ presented pericentromeric $\mathrm{CH}$ extending along the two chromosome arms, and $\mathrm{Y}_{3}$ possessed pericentromeric $\mathrm{CH}$ on the short arm (Figures 3a and $3 b$ ).

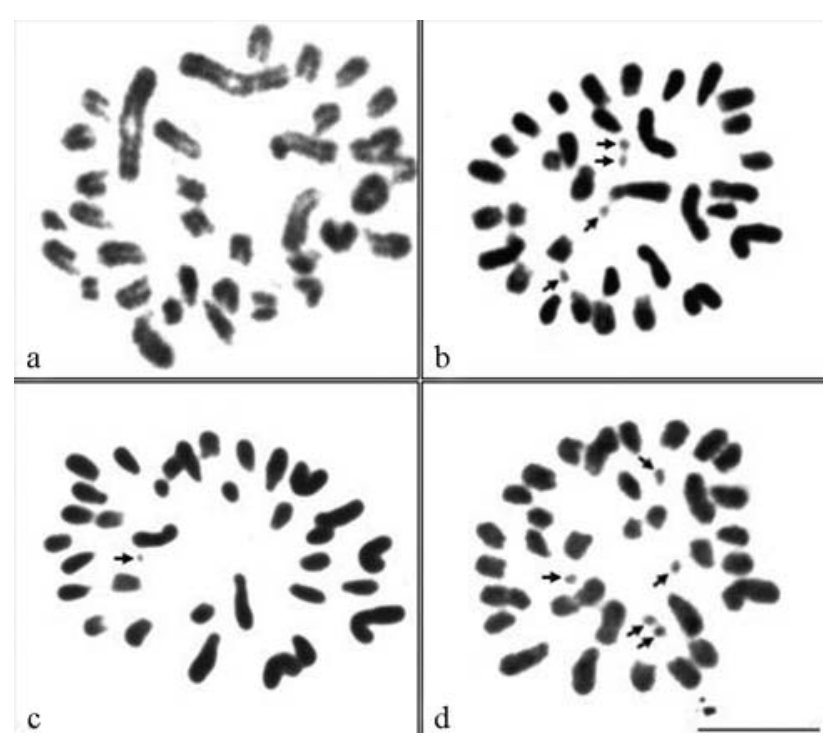

Figure 1 - Spermatogonial metaphases of Euchroma gigantea with different chromosome numbers: $2 n=36$ (a), $2 n=34$ (b), $2 n=33$ (c), and $2 n=32$ (d). Arrows indicate punctiform $\mathrm{B}$ chromosomes in $\mathrm{b}, \mathrm{c}$ and $\mathrm{d}$. Bar $=10 \mu \mathrm{m}$. 


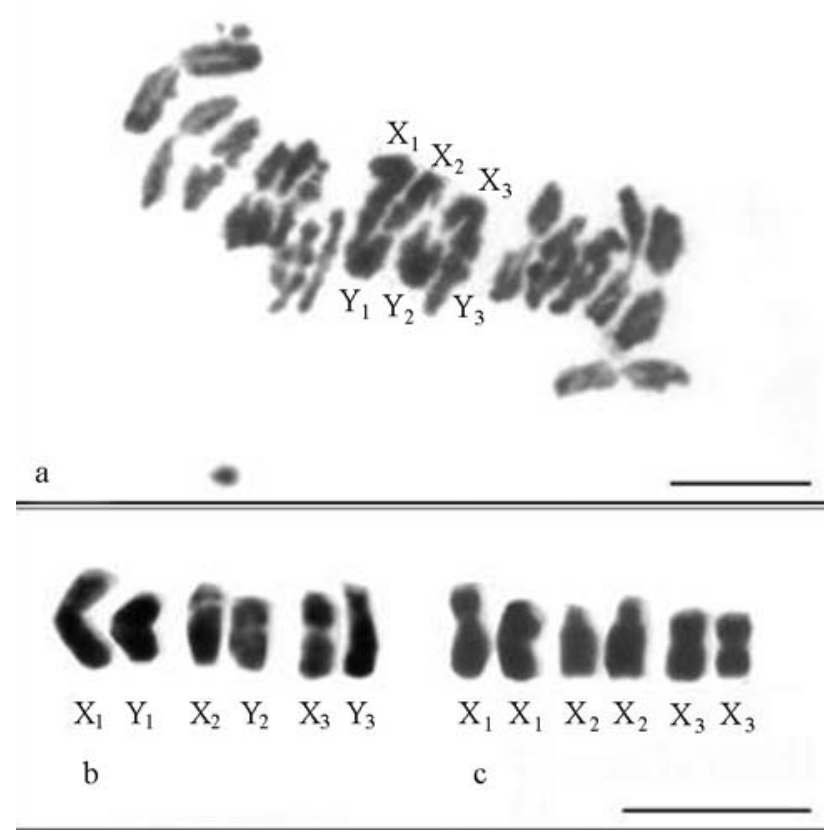

Figure 2 - Conventionally stained meiotic and mitotic chromosomes of Euchroma gigantea. (a) Metaphase I with $2 \mathrm{n}=34$. Observe the alternate chain formed by the $\left(X_{1} Y_{1} X_{2} Y_{2} X_{3} Y_{3}\right)$ sex chromosomes. (b) and (c) Sex chromosomes of a male and of a female, respectively. Bar $=10 \mu \mathrm{m}$.

Silver nitrate staining of cells at the beginning of prophase I revealed labeling of the sex chromosome chain (Figure 3c). Analysis of spermatogonial metaphases by FISH using a ribosomal probe demonstrated the presence of two rDNA sites on different chromosomes. During metaphase I the sites were found to be associated with the sex chain, more precisely with chromosomes $\mathrm{X}_{1}$ and $\mathrm{X}_{2}$ (Figures $3 \mathrm{~d}$ and $3 \mathrm{e}$ ).

\section{Discussion}

Comparison between the few Buprestidae species studied cytologically clearly shows the chromosome heterogeneity of this family, with the chromosome number ranging from $2 \mathrm{n}=12$ to $2 \mathrm{n}=46$ represented by different karyotypes: $12, \mathrm{Xy}_{\mathrm{p}} ; 14$, neoXY; $16, \mathrm{Xy}_{\mathrm{p}} ; 18$, neoXY; 18 , $\mathrm{Xy}_{\mathrm{r}} ; 20, \mathrm{Xy}_{\mathrm{p}} ; 20, \mathrm{XY}$; 20, Xy; 20, neoXY; 21, X0; 22, Xур 24, neoXY; 24, $\mathrm{X}_{1} \mathrm{X}_{2} \mathrm{X}_{3} \mathrm{Y}_{1} \mathrm{Y}_{2} \mathrm{Y}_{3} ; 26, \mathrm{XY} ; 26$, neoXY; 26, $\mathrm{X}_{1} \mathrm{X}_{2} \mathrm{X}_{3} \mathrm{Y}_{1} \mathrm{Y}_{2} ; 40, \mathrm{XY}$; and 38-46 (Asana et al., 1942; Smith and Virkki, 1978; Mesa and Fontanetti, 1984; Karagyan and Kuznetsova, 2000; Karagyan, 2001). The karyotype variation found among $E$. gigantea specimens collected in northeastern Brazil enlarge the numerical variation described for the Buprestidae and demonstrates the presence of a wide autosomal polymorphism in this species. On the other hand, the karyotype variation observed among specimens from the southeastern region (Mesa and Fontanetti, 1984) and those analyzed here may indicate the occurrence of different species of Euchroma which, until now, has been considered to be a monotypic genus.

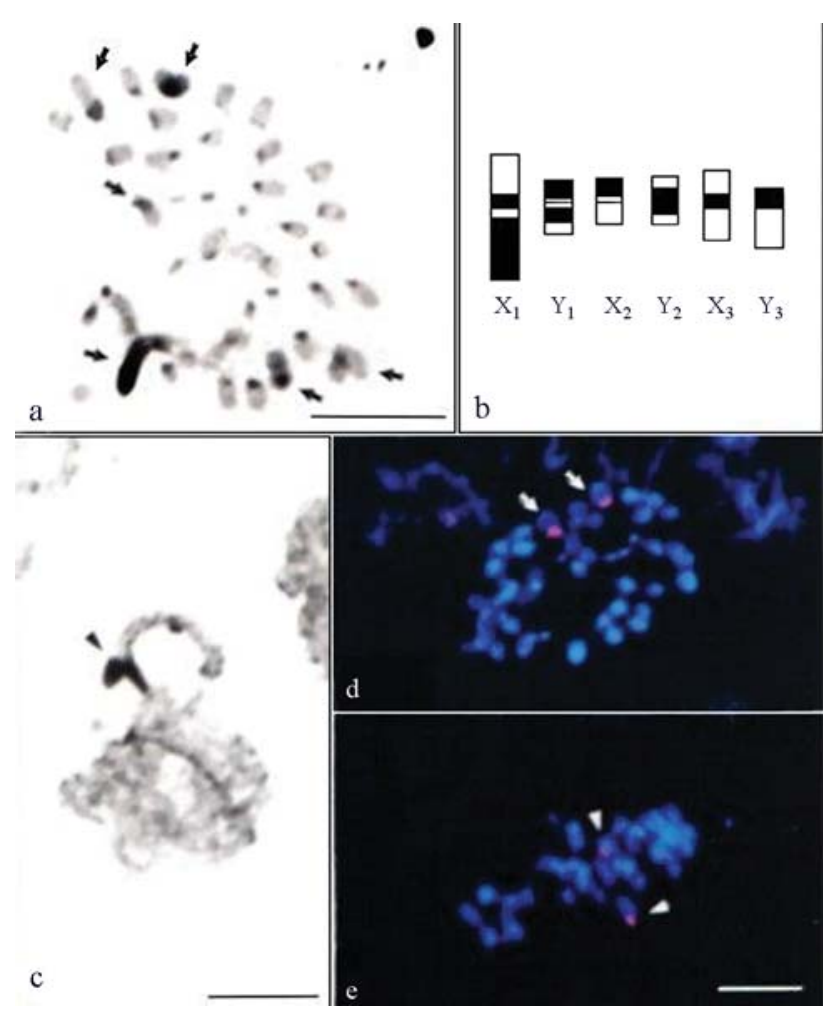

Figure 3 - C-banding pattern, $\mathrm{AgNO}_{3}$ staining and fluorescent in situ hybridization with a ribosomal probe of meiotic and mitotic chromosomes of Euchroma gigantea. (a) Mitotic metaphase of a male. (b) Schematic representation of the C-banding pattern of the sex chromosomes. The arrows indicate the sex chromosomes. (c) Zygotene. The arrowhead indicates the $\mathrm{AgNO}_{3}$-stained nucleolar organizer region. (d) Spermatogonial metaphase showing the two rDNA sites. (e) Metaphase I indicating the location of the sites on the $\mathrm{X}_{1}$ and $\mathrm{X}_{2}$ chromosomes (arrowheads). Bar $=10 \mu \mathrm{m}$.

In Coleoptera, examples of chromosome polymorphisms have been observed for different species of Ipis $2 \mathrm{n}=16$ to $2 \mathrm{n}=32$, Pissodes $2 \mathrm{n}=25$ to $2 \mathrm{n}=34$, Mulsantina $2 \mathrm{n}=12$ to $2 \mathrm{n}=20$, and Chilocorus $2 \mathrm{n}=19$ to $2 \mathrm{n}=25$. This variability has been attributed to the occurrence of centric fusions, fissions and pericentric inversions (Smith and Virkki, 1978; Boyce et al., 1994). The genus Chilocorus has a basic chromosome number of $2 \mathrm{n}=22$ and is found in North America, India and Europe. For example, Chilocorus stigma populations from North America present a multiple sex determination mechanism $\left(\mathrm{X}_{1} \mathrm{X}_{2} \mathrm{Y}\right)$, wide chromosomal polymorphism $(2 n=19$ to $2 n=25)$ and supernumerary chromosomes. Centric fusion and fission have been proposed to explain the karyotype variation observed in this species (Smith and Virkki, 1978).

Comparative karyotype analysis between our sample of E. gigantea from Pernambuco and specimens collected in the Brazilian state of São Paulo (Mesa and Fontanetti, 1984) throws some light on the chromosome evolution of this species. The known variation in chromosome constitution suggests that the most primitive karyotype would be $2 n=36$ from which successive centric fusions resulted in derived karyotypes, starting with a single homozygous fu- 
sion to produce $2 \mathrm{n}=34$, followed by two fusions to produce $2 \mathrm{n}=32$, five fusions to produce $2 \mathrm{n}=26$ and six fusions to produce $2 \mathrm{n}=24$.

Centric fusions have been considered the most common rearrangement between species or chromosomal races. King (1993) has suggested that this type of karyotypic change frequently results in karyotypes with balanced polymorphism. Several species of animals, especially mammals such as the African pigmy mouse Mus Nannomys minutoides, presenting six cytotypes characterized by different autosome-autosome fusions (Castiglia et al., 2006), and the Rhogeesa tumida-Rhogeesa parvula bat complex which possesses seven different cytotypes $(2 \mathrm{n}=30,32,34$, 42,44 and 52) which differ in regard to successive chromosomal fusions and which Baker et al. (1985) suggests correspond to different species. There are also examples in insects, such the orthopteran Hemideina crassidens which has two karyotypes $(2 \mathrm{n}=15, \mathrm{XO}+1 \mathrm{~B}$ or $2 \mathrm{Bs} ; 2 \mathrm{n}=19, \mathrm{XO})$ resulting from two Robertsonian translocations (MorganRichards, 2000) and also in coleopterans Poecilus copreus $(2 \mathrm{n}=43,44)$, Platysma negrita $(2 \mathrm{n}=40,41,43,46)$, Calathus fuscipes $(2 \mathrm{n}=37,39)$, Amara familiaris $(2 \mathrm{n}=33$, $34)$, Harpalus serripes $(2 n=37,39)$ and species of the genus Timarcha in which the diploid number varies from 2n $=18$ to 44 (Serrano, 1981; Gómez-Zurita et al., 2004).

On the other hand, cannot affirm that the fusions seen by us are the main rearrangement involved in the chromosomal evolution of E. gigantea, because molecular and biogeographic studies that establish ancestral groups do not exist. Another possible alternative is the rearrangement commenced with the $2 n=24, X_{1} X_{2} X_{3} Y_{1} Y_{2} Y_{3}$ karyotype, in which autosome-sexual chromosome translocations, autosome-autosome and pericentric inversions were initially involved generating the karyotypes described by Mesa and Fontanetti (1984) with $2 \mathrm{n}=24, \mathrm{X}_{1} \mathrm{X}_{2} \mathrm{X}_{3} \mathrm{Y}_{1} \mathrm{Y}_{2} \mathrm{Y}_{3}$ and a fission producing the $2 n=26, X_{1} X_{2} X_{3} Y_{1} Y_{2}$ Karyotype. Based on the karyotypes described in the present paper it seems that four fissions had probably occurred to produce $2 \mathrm{n}=32$, $\mathrm{X}_{1} \mathrm{X}_{2} \mathrm{X}_{3} \mathrm{Y}_{1} \mathrm{Y}_{2} \mathrm{Y}_{3}$, five fissions to produce $2 \mathrm{n}=34$, $X_{1} X_{2} X_{3} Y_{1} Y_{2} Y_{3}$ and six fissions to produce $2 n=36$, $X_{1} X_{2} X_{3} Y_{1} Y_{2} Y_{3}$. In addition to the rearrangements described above, we detected the occurrence of successive pericentric inversions responsible for the alteration in the proportion of chromosomal arms in the different karyotypes presented by E. gigantea. Karagyan et al. (2004) have pointed out that it is not yet possible to infer the ancestral karyotype for the Buprestidae, although a similarity has been proposed with the ancestral karyotype $(2 \mathrm{n}=20, \mathrm{Xyp})$ described for the Coleoptera in general and also observed in different species of the subfamilies Chrysochroinae, Buprestinae and Agrilinae but there is as yet no concrete evidence to define the ancestral karyotype for E. gigantea. The different karyotypes of $E$. gigantea and the probable rearrangements involving to produce the current karyotypes found in this species is shown in Figure 4.
Mesa and Fontanetti (1984) have pointed out that successive translocations involving autosomes and sex chromosomes were responsible for the formation of the complex $3 \mathrm{X}+3 \mathrm{Y}$ mechanism found in E. gigantea, which probably derived from an $\mathrm{Xy}$ or $\mathrm{XO}$ system. The presence of the $\mathrm{X}_{1} \mathrm{X}_{2} \mathrm{X}_{3} \mathrm{Y}_{1} \mathrm{Y}_{2} \mathrm{Y}_{3}$ sex mechanism in all karyotype compositions found in E. gigantea suggests that this mechanism is old and well-established in this species.

Among coleopterans, the Buprestidae is the family with the largest number of supernumerary chromosomes (Smith and Virkki, 1978; Mesa and Fontanetti, 1984). We observed 16 to 32 supernumerary chromosomes in our southeastern Brazilian E. gigantea sample, while Mesa and Fontanetti (1984) have reported that $E$. gigantea from this region showed the lowest diploid number $(2 \mathrm{n}=24$ and 26). However, in our study, the E. gigantea specimens from northeastern Brazil showed extensive autosomal polymorphism and also the largest diploid number $(2 \mathrm{n}=32$ to 36$)$, as well as a markedly smaller number (five) of supernumerary chromosomes. Derivation from A chromosomes is the most widely accepted of the various hypotheses on the origin of B chromosomes, which could have arisen either from centromeres remaining after chromosome fusions or from amplified pericentromeric fragments (Jones and Rees, 1982; Camacho et al., 2000). Events of these types might have been involved in the origin of B chromosomes in $E$. gigantea. Colombo and Remis (1997) have presented data on the grasshopper Sinipta dalmani showing that B chromosomes arise from centric fragments produced from the high frequency of karyotypic rearrangements such as inversions and centric fusions.

As in other coleopteran species, the pattern of $\mathrm{CH}$ distribution in E. gigantea is predominantly pericentromeric but we found that in this species the autosomal $\mathrm{CH}$ blocks were small and some autosomal pairs possessed minute terminal blocks, in contrast to the sex chromosomes which were characterized by large $\mathrm{CH}$ blocks. Atypical patterns of heterochromatin distribution have been described in other coleopterans. Some Carabidae species, such as Acapulcus Stenolophus teutonus, Acapulcus elegans and Bembidion minimum, not only possess large $\mathrm{CH}$ blocks on the autosomes and have completely heterochromatic X chromosome but also show C-band heteromorphism and terminal and subterminal $\mathrm{CH}$ blocks (Rozek, 1992; Rozek and Rudek, 1992). For example, Vitturi et al. (1996) observed pericentromeric $\mathrm{CH}$ blocks in two Blaps species, whereas Blaps gibba presented an additional proximal and interstitial block on chromosome pair 1 and terminal blocks on pairs 9 and 12 .

Our silver nitrate staining and FISH results for $E$. gigantea agree with the pattern observed in other coleopterans that possess a multiple sex mechanism (Galián et al., 1995; Vitturi et al., 1996; Galián and Hudson, 1999) and for which the rDNA sites are located on the sex chromosomes. In general, the species analyzed so far have shown 

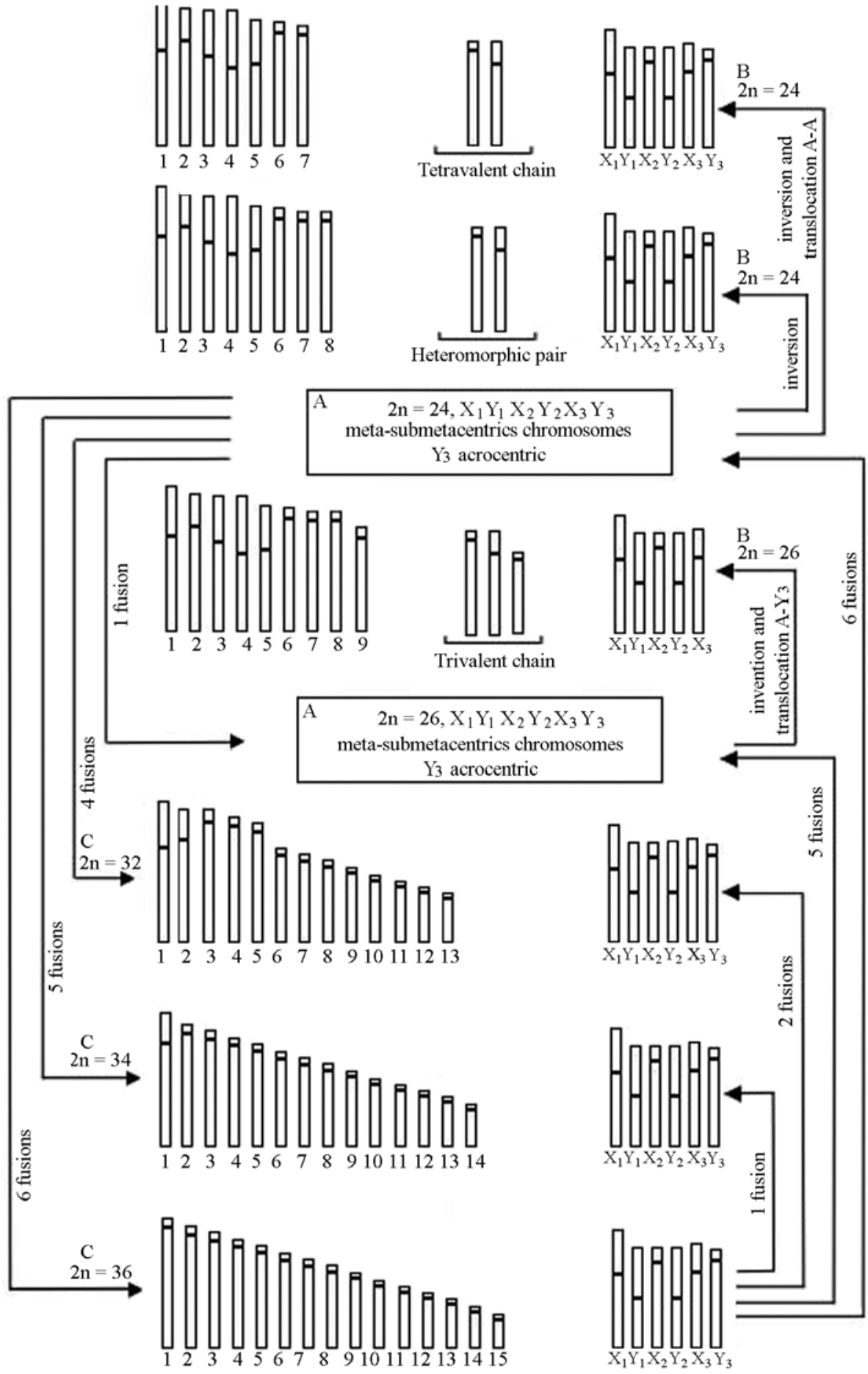

Figure 4 - Schematic representation of the different chromosome numbers observed in Euchroma gigantea and of the probable rearrangements that occurred during the chromosome evolution of this species. A - hypothetical karyotypes; B - karyotypes described by Mesa and Fontanetti (1984) and $\mathrm{C}$ - karyotypes observed in this work.

two hybridization signals, except for $B$. gibba which shows seven to eight signals scattered over the sex multivalent (Vitturi et al., 1996). In contrast, preferential staining of the autosomes is observed in representatives of the Carabidae (Galián et al., 1995; De La Rua et al., 1996; Galián and Hudson, 1999; Sanchez-Gea et al., 2000), Geotrupidae
(Vitturi et al., 1999) and Scarabaeidae (Colomba et al., 2000) and which possess a simple sex mechanism.

To better understand the chromosome evolution of $E$. gigantea, studies investigating specimens from the North and Center-West region of Brazil are fundamental, in addition to the analysis of other specimens from the Southeast 
mainly employing FISH with a telomeric probe. Furthermore, a taxonomic revision of the genus including subspecies and varieties from different geographic regions, together with the available cytogenetic analysis, will be of great importance for better understanding the status of the genus Euchroma.

\section{Acknowledgments}

We are very grateful to the following: Dr. Cleide Costa (Museu de Zoologia, Universidade de São Paulo, Brazil) for laboratory facilities, advice and analysis of morphological variation in Euchroma gigantea; Dr. Marcelo Guerra, Departamento de Botânica, UFPE, for Laboratory facilities for the execution of the FISH; Dr. Alejo Mesa and Dr. Aline Alexandrino for suggestions and critical revision of the manuscript; and Francisca Tavares de Lira for technical assistance. This research was supported by the Brazilian agencies Conselho Nacional de Desenvolvimento Científico e Tecnológico (CNPq) and Fundação de Amparo à Ciência e Tecnologia do Estado de Pernambuco (FACEPE).

\section{References}

Asana JJ, Makino S and Niiyama N (1942) A chromosome survey of some Indian insects. IV. On the sex chromosomes of some species of beetles (Coleoptera). Cytologia 12:187-205.

Baker RJ, Bickham JW and Arnold MI (1985) Chromosomal evolution in Rhogeessa (Chiroptera, Vespertilionidae): Possible speciation by centric fusions. Evolution 39:233-243.

Boyce TM, Michael EZ and Aquadro CF (1994) Mitocondrial DNA in the Bark weevils: Phylogeny and Evolution in the Pissodes strobi Species Group (Coleoptera, Curculionidae). Mol Biol Evol 11:183-194.

Camacho JPM, Sharbel TF and Beukeboom LW (2000) B-chromosome evolution. Phil Trans R Soc Lond 355:163-178.

Castiglia R, Garagna S, Merico V, Oguge N and Corti M (2006) Cytogenetics of a new cytotype of African Mus (subgenus Nannomys) minutoides (Rodentia, Muridae) from Kenya: Cand G-banding and distribution of (TTAGGG)n telomeric sequences. Chromosome Res 14:587-594.

Colomba MS, Vitturi R and Zunino M (2000) Karyotype analyzes, banding, and fluorescent in situ hybridization in the Scarab beetle Gymnopleurus sturmi McLeady (Coleoptera, Scarabaeoidea, Scarabaeidae). J Hered 91:260-264.

Colombo PC and Remis MI (1997) On the origin of B-chromosomes neoXY systems and $\mathrm{X}$-like supernumeraries in Orthoptera. Caryologia 50:151-162.

De La Rúa P, Serrano J, Hewitt M and Galián J (1996) Physical mapping of rDNA genes in the ground beetle Carabus and related genera (Carabidae, Coleoptera). J Zool Syst Evol Res 34:95-101.

Galián J and Hudson P (1999) Cytogenetic analysis of Australian tiger beetles (Coleoptera, Cicindelidae): Chromosome number, sex-determinning system and localization of rDNA genes. J Zool Syst Evol Res 37:1-6.

Galián J, De la Rúa P, Petitpierre E and Juan C (1995) Localization and activity of rDNA genes in tiger beetles (Coleoptera, Cicindelinae). Heredity 74:524-530.
Gómez-Zurita J, Pons J and Petitpierre E (2004) The evolutionary origin of a novel karyotype in Timarcha (Coleoptera, Chrysomelidae) and general trends of chromosome evolution in the genus. J Zool Evol Res 42:332-341.

Karagyan GA (2001) Ag-banded karyotypes in six species of jewel-beetles (Buprestidae, Coleoptera). Folia Biol 49:4248.

Karagyan GA and Kuznetsova VG (2000) Chromosome number and sex chromosome systems in Buprestid beetles (Coleoptera, Buprestidae). Entomol Rev 80:38-49.

Karagyan GA, Kuznetsova VG and Lachowska D (2004) New citogenetic data on Armenian Buprestids (Coleoptera, Buprestidae) with a discussion of karyotype variation within the family. Folia Biol 52:151-158.

King M (1993) Species Evolution, the Role of Chromosome Change. Cambridge University Press, New York, 336 pp.

Jones RN and Rees H (1982) B Chromosomes. Academic Press, New York, 266 pp.

Mesa A and Fontanetti CS (1984) Multiple sex chromosomes, autosomal polymorphism and high number of S chromosomes in Euchroma gigantea L. 1735 (Coleoptera, Buprestidae). Rev Bras Genet 4:629-637.

Morgan-Richards M (2000) Robertsonian translocations and B chromosomes in the Wellington tree weta, Hemideina crassidens (Orthoptera, Anostostomatidae). Hereditas 132:49-54.

Moscone EA, Matzke MA and Matzke AJM (1996) The use of combined FISH/GISH in conjunction with DAPI counterstaining to identify chromosomes containing transgene inserts in amphidiploid tobacco. Chromosoma 105:231-236.

Nichols ML (1910) The spermatogenesis of Euchroma giagantea. Biol Bull 19:167-179.

Obenberger J (1928) Opuscula buprestologica. I Arch Natur 92:113-224

Panzera F, Mazella MC and De Vaio ES (1983) Cytological studies on three species of neotropical cassidines (Coleoptera, Chrysomelidae). Genetica 62:61-68.

Postiglioni A, Da Silva A, Ponce de Leon R and De Vaio ES (1987) Three species of Heilipodus (Coleoptera, Curculionidae) with different karyotypes and sex chromosome systems. Genetica 75:213-218.

Rozek M (1992) Karyological analysis of Acupalpus (Stenolophus) teutonus (Schrank) and Pogonus presicus (Chaud.) (Coleoptera, Carabidae) Folia Biol 40:113-118.

Rozek M and Rudek Z (1992) Karyotype analysis and C-banding pattern in two species of Carabid (Coleoptera, Carabidae). Folia Biol 40:47-52.

Rufas JS, Giménez-Ábian J, Suja JA and Garcia De la Vega C (1987) Chromosome organization in meiosis revealed by light microscope analysis of silver-stained "cores". Genome 29:706-712.

Sánchez-Gea JF, Serrano J and Galián J (2000) Variability in rDNA loci Iberian species of the genus Zabrus (Coleoptera, Carabidae) detected by fluorescence in situ hybridization. Genome 43:22-28.

Serrano J (1981) Chromosome number and karyotypic evolution of Caraboidea. Genetica 55:51-60.

Serrano J, Galián J and Reys-Castillo P (1998) Karyotypic evolution and phylogeny of Mexican Passalidae (Coleoptera, Polyphaga, Scarabaeoidea). J Zool Syst Evol Res 36:159167. 
Smith SG and Virkki N (1978) Coleoptera. In: John B (ed) Animal Cytogenetics. Borntraeger Verl., Berlin, 366 pp.

Sumner AT (1972) A simple technique for demonstrating centromeric heterocromatin. Exp Cell Res 75:304-306.

Unfried I and Gruendler P (1990) Nucleotide sequence of the 5.8S and $25 \mathrm{~S}$ rRNA genes and of the internal transcribed spacers from Arabdopsis thaliana. Nucleic Acids Res 18:4011.

Unfried I, Stocker U and Gruendler P (1989) Nucleotide sequence of the 18S rRNA gene from Arabdopsis thaliana. Nucleic Acids Res 17:7513.

Virkki N (1984) Chromosomes in evolution of Coleoptera. In: Sharma AK and Sharma (eds) Chromosomes in Evolution of Eukaryotic Groups. CRC Press, Florida, 260 pp.

Virkki N and Santiago-Blay A (1993) Trends of karyotype evolution in neotropical Oedionychina (Coleoptera, Chrysomelidae, Alticinae). Hereditas 119:263-283.
Vitturi R, Catalano E, Sparacio I, Colomba MS and Morello A (1996) Multiple chromosome sex systems in the darkling beetles Blaps gigas and Blaps gibba (Coleoptera, Tenebrionidae). Genetica 97:225-233.

Vitturi R, Colomba MS, Barbieri R and Zunino M (1999) Ribosomal DNA location in the scarab beetle Thorectes intermedius (Costa) (Coleoptera, Geotrupidae) using banding and fluorescent in situ hybridization. Chromosome Res 7:255-260.

Wahrman J, Nezer R and Freund O (1973) Multiple sex chromosome mechanism with segregation bodies. Chromosomes Today 4:434.

Associate Editor: Yatiyo Yonenaga-Yassuda

License information: This is an open-access article distributed under the terms of the Creative Commons Attribution License, which permits unrestricted use, distribution, and reproduction in any medium, provided the original work is properly cited. 